\title{
EPs 7630, a Herbal Drug Preparation for Treating Acute Bronchitis in Children and Adults
}

\author{
H. Matthys ${ }^{1}$ and W. Kamin ${ }^{2}$ \\ ${ }^{1}$ Medical Director emeritus, Department of Pneumology, University Hospital Freiburg, \\ ${ }^{2}$ Clinic for Paediatrics, Evangelic Hospital Hamm,
}

\section{Introduction}

Germany

Herbal medicines play an increasingly important role in the perception of physicians and patients looking for equally effective, albeit safer approaches to conventional management of acute bronchitis. A no antibiotic or delayed antibiotic prescribing strategy to reduce the inappropriate prescribing of antibiotics for respiratory tract infections (RTI) has been advocated since the late 1990's (Little, 2005). In the light of inappropriate antibiotic use in this indication especially in children and increasing drug resistance rates worldwide, the need for an alternative remedy is crucial (Abbas et al., 2010). There is encouraging evidence derived from high quality randomised clinical trials (RCTs) that EPs 76301, a herbal drug preparation from the roots of Pelargonium sidoides widely used in several countries for the treatment of RTIs in children ( $\geq 1$ year of age) and adults, is effective in patients with acute bronchitis.

\section{EPs 7630 - from traditional herbal medicine to modern phytotherapy}

Pelargonium sidoides, a member of the Geraniaceae family, can readily be recognized by its dark-red, almost black flowers, the large, heart-shaped leaves and thick rhizomes (Figure 1). The plant is native to the coastal regions of South Africa. For centuries, crude root drug of initially unknown botanical origin has been traditionally used among Zulus of South Africa for the treatment of pulmonary disease and tuberculosis. In the late 19th century, the Englishman Charles H. Stevens introduced the crude herbal drug as "Stevens' cure" in Europe after he had been cured from tuberculosis. In the 1920's, the former missionary and physician Dr. A. Sechehaye treated around 800 tuberculosis patients with the drug and published his 9-year experience concluding that clear healing effects could be seen (Sechehaye, 1937). It was not before the 1970's, however, that professional search and initial chemical and taxonomic investigations undertaken by German researchers revealed that the crude herbal drug must have originated from Pelargonium species, i.e. P. sidoides DC and the closely related P. reniforme Curt (Bladt \& Wagner 2007; Kolodziej 2007; Brendler \& van Wyk, 2008). The chemical profile of the Pelargonium sidoides root was identified and as research progressed, a proprietary extraction technique was developed and perfected to

${ }^{1} \mathrm{EPs}^{\circledR} 7630$ is the active ingredient of the product Umckaloabo ${ }^{\circledR}$ (ISO Arzneimittel, Ettlingen, Germany) 
yield the herbal drug preparation EPs 7630 from the roots of Pelargonium sidoides (1:8-10), extraction solvent: ethanol $11 \%(\mathrm{w} / \mathrm{w})$.
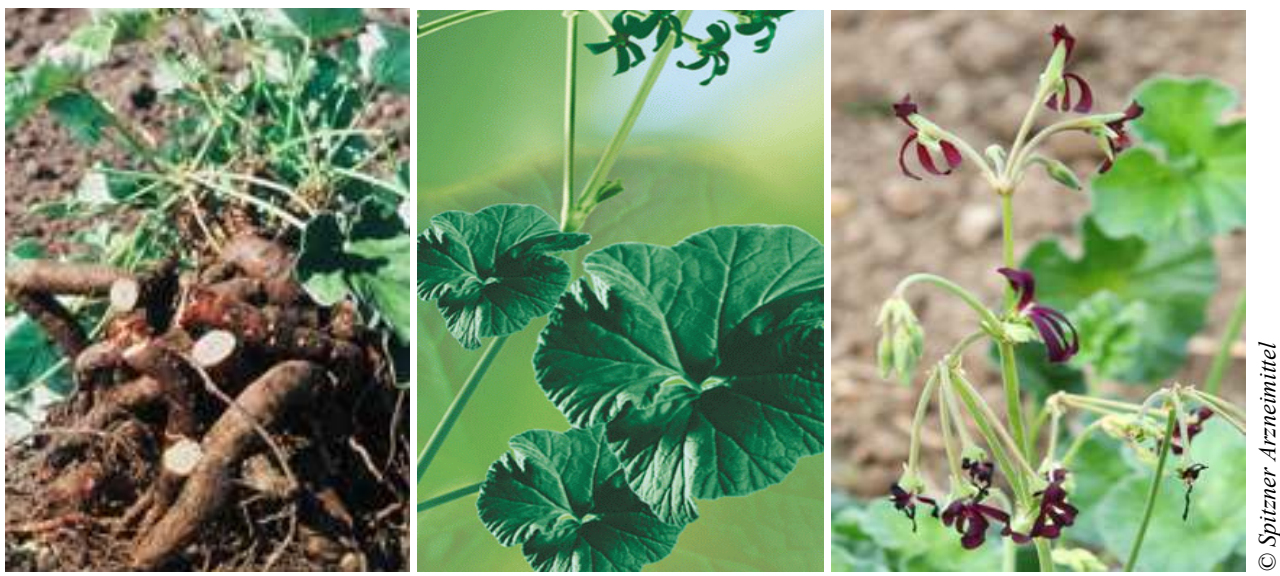

Fig. 1. Pelargonium sidoides (rhizomes, leaves and flowers)

\section{Phytochemistry and pharmacology}

\subsection{Constituents of the Pelargonium sidoides preparation EPs $\mathbf{7 6 3 0}$}

Up to now, about three-quarters of the compositional profile of EPs 7630 is known. EPs 7630 contains primarily phenolic and polyphenolic compounds, proteins, minerals, coumarin derivatives (coumarin sulphates and coumarin glycosides) and a number of miscellaneous uncommon metabolites (Schötz et al., 2008) (Figure 2). The 7-hydroxycoumarin (including umckalin) derivatives differ in chemical structure from the known anticoagulant coumarins and are not associated with anticoagulant activity or interaction with warfarin and its pharmacokinetics (Koch \& Biber, 2007).

Pharmacological studies have suggested that the mechanism of action of EPs 7630 is multifactorial including antibacterial and antiviral potencies and notable immune modulatory capabilities as well as cytoprotective effects (Kolodziej et al., 2003; Kolodziej \& Kiderlen, 2007; Thäle et al., 2011; Michaelis et al., 2011). In vitro studies with EPs 7630 demonstrated a moderate direct antibacterial activity against various gram-positive and gram-negative bacteria (Kolodziej et al., 2003), a strong indirect antibacterial activity like inhibition of interaction between group A-streptococci and host epithelia (Conrad et al., 2007b), improved phagocytosis, improved oxidative burst and intracellular killing by human peripheral blood phagocytes (Conrad et al., 2007a) and antiviral properties, e.g. interference on replication of a panel of seasonal respiratory viruses such as H1N1 (Michaelis et al., 2011). Furthermore, in-vitro studies have found that EPs 7630 exerts a cytoprotective effect against virus-induced cell destruction and also increases release of antimicrobial peptides (also known as defensins) from neutrophilic granulocytes (Koch \& Wohn, 2007; Kolodziej \& Schulz, 2003). The immune-modulatory activities are mainly mediated by the release of tumour-necrosis factor (TNF- $\alpha$ ) and nitric oxide (Kolodziej \& Kiderlen, 2007; Thäle et al., 2011), stimulation of interferon- $\beta$ (Kolodziej et al., 2003) and an increase in natural killer cell activity (Koch et al., 2002). In cell cultures, EPs 7630 has been found to stimulate the ciliary 
beat frequency (Neugebauer et al., 2005), which may support a secromotoric effect during acute respiratory tract infections. Finally, EPs 7630 inhibits the lipopolysaccharide-induced sickness behaviour in mice in vivo (Nöldner \& Schötz, 2007).

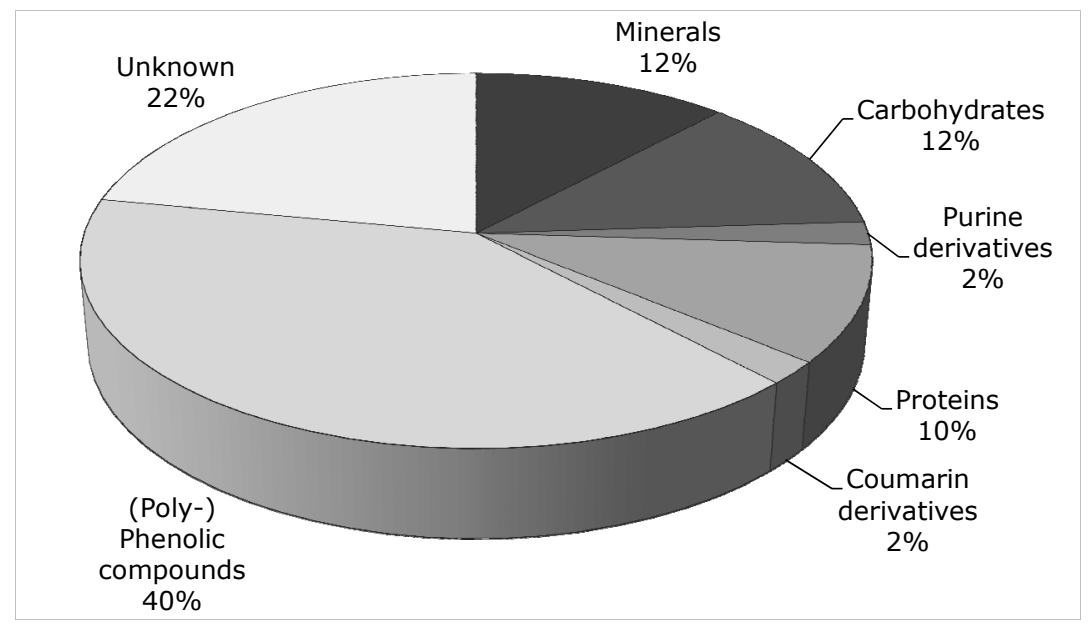

Fig. 2. Constituents of Pelargonium sidoides root preparation EPs 7630

\section{Clinical research in acute bronchitis}

The efficacy and safety of EPs 7630 in the treatment of acute respiratory tract infections has been studied in over 3,500 patients of placebo-controlled double-blind clinical studies and in over 5,500 patients of open-label and non-interventional (post-marketing surveillance) studies. Out of the total of over 9,000 patients, about 4,000 were children and adolescents. EPs 7630 has been shown to be effective and safe in the treatment of acute upper respiratory tract infections, including bronchitis, tonsillopharyngitis, sinusitis, and common cold (Brown, 2009). A meta-analysis of randomised clinical trials with EPs 7630 in acute respiratory tract infections published by the Cochrane Collaboration (Timmer et al., 2008) showed that EPs 7630 was effective in alleviating the disease-specific symptoms of acute bronchitis, particularly coughing and sputum production. In acute sinusitis and common cold, EPs 7630 also was effective in resolving all symptoms including headaches and nasal discharge. Another meta-analysis reviewed 6 randomised, controlled clinical studies investigating EPs 7630 in acute bronchitis in both adults and children (Agbabiaka et al., 2008). While one double-dummy study compared EPs 7630 against N-acetylcysteine, the other 5 were placebo-controlled trials. Treatment duration was 7 days. The primary outcome variable was the change in the total Bronchitis Severity Score (BSS) from baseline to the end of the study. The BSS consists of 5 items which are the most important features associated with acute bronchitis and considered to be of clinical relevance (Franks \& Gleiner, 1984; Knutson \& Braun, 2002; Macfarlane et al., 2002; Williamson, 1984), i.e. coughing, sputum production, pulmonary rales at auscultation, chest pain while coughing, and dyspnoea, each symptom being scored by the investigator using a 5-point rating scale ranging from 0 (not present) to 4 (very severe). The meta-analysis showed that EPs 7630 compared to placebo significantly decreased the total BSS within 7 days of treatment (calculated weighted mean 
differences 2.80 points, $95 \%$ confidence interval 2.44-3.15) with improvement in individual components of the BSS.

Up to now, more than 2,500 patients (including about one third adolescents and children, aged $\geq 1$ year) have been included into randomised placebo-controlled clinical trials in order to investigate the efficacy and safety of EPs 7630 in acute bronchitis. The latest high quality studies are outlined in the following.

\subsection{Major randomised clinical trials in adults}

All of the three recently published major clinical studies in adults suffering from acute bronchitis were randomised, double-blind, placebo-controlled multicentre trials investigating the efficacy and tolerability of EPs 7630 in patients ( $\geq 18$ years) (Chuchalin et al., 2005; Matthys \& Heger 2007; Matthys et al. 2010a,b). Major inclusion criteria in all three trials were a total BSS of $\geq 5$ points and acute bronchitis symptoms having started $\leq 48$ hours prior to study entry. The individual treatment period lasted 7 days including three visits (day 0 , day 3 to 5 , and day 7 ). In case of a fever $\left(\geq 39^{\circ} \mathrm{C}\right)$, paracetamol tablets $(500 \mathrm{mg}$ ) were allowed (maximum 3 tablets per day). Primary endpoint in all three studies was the change in the total BSS from baseline to day 7. Secondary outcome measures were: Change of individual symptoms of the BSS; change in general symptoms (hoarseness, headache, limb pain and fatigue/exhaustion) with the following definition of change: complete remission (symptoms present on day 0 had completely resolved on day 7), improvement (any decrease in symptom intensity from day 0 to day 7 , except remission), no change (no change in symptom intensity from day 0 to day 7), deterioration (any increase in symptom intensity from day 0 to day 7); treatment outcome assessed by both the patient and the investigator using the Integrative Medicine Outcomes Scale (IMOS) which is widely used in conventional research as well as in complementary and alternative medicine research and describes the general health status of the patient (Steinsbekk et al., 1999). It consists of 5 items: complete recovery, major improvement, slight to moderate improvement, no change, and deterioration; patient's satisfaction with treatment using the Integrative Medicine Patient Satisfaction Scales (IMPSS) which describes the patient's satisfaction with the treatment and consists of 5 items: very satisfied, satisfied, neutral, dissatisfied, very dissatisfied (Steinsbekk et al., 1999); onset of treatment effect; duration of activity limitation and duration of inability to work; intake of paracetamol and the general health status using health-related quality of life questionnaires (EQ-5D and EQ VAS (EQ-5D, 2011), SF-12 Health Survey (Ware et al., 1996)). In addition, adverse events (AEs), laboratory safety parameters, and vital parameters were recorded.

In the trial reported by Chuchalin and colleagues (2005), 124 adults ( $\geq 18$ years) suffering from acute bronchitis received either $3 \times 30$ drops/d EPs 7630 solution $(n=64)$ or matched placebo $(n=60)$ for 7 days. At baseline, the mean total BSS was similar in both treatment groups (Figure 3). According to the intention-to-treat analysis at day 7, the total BSS (mean \pm standard deviation) decreased by $7.2 \pm 3.1$ points in the EPs 7630 group compared with $4.9 \pm 2.7$ points in the placebo group $(\mathrm{p}<0.0001)$. The treatment effect was already significantly larger at the first follow-up contact (day 3-5) with a total BSS of 4.4 \pm 2.2 points in the EPs 7630 group and $6.2 \pm 2.5$ points in the placebo group $(\mathrm{p}<0.0001)$. On day 7 , the rate of complete remission from individual symptoms of the BSS was considerably higher in the EPs 7630 group. Pulmonary rales at auscultation, for instance, disappeared in 55/60 patients $(91.7 \%)$ in the EPs 7630 group compared with $29 / 59$ patients $(49.2 \%)$ in the placebo group $(\mathrm{p}<0.0001)$, chest pain while coughing resolved in $55 / 58$ patients $(94.8 \%)$ of the EPs 7630 
group and $29 / 52$ patients $(55.8 \%)$ of the placebo group, respectively $(\mathrm{p}<0.0001)$, and for coughing, the rate of complete remission was also significantly higher in the EPs 7630 group compared to the placebo group ( $31.3 \%$ versus $5.0 \%$; $<<0.0001)$. Furthermore, all five general symptoms showed higher recovery and improvement rates in the EPs 7630 group compared with placebo. According to the IMOS assessment carried out by the investigator on day 7 , 54/64 patients $(84.4 \%)$ in the EPs 7630 group were judged as completely recovered or having major improvement compared with $18 / 60$ patients $(30.0 \%)$ in the placebo group. The IMOS assessment by the patient showed similar results. Correspondingly, 51/64 patients (79.7\%) in the EPs 7630 group and 26/60 patients (43.3\%) in the placebo group were satisfied with their treatment according to the IMPSS $(\mathrm{p}<0.0001)$. The results also indicated a better health-related quality of life according to EQ-5D, EQ VAS and SF-12 Health Survey for those patients treated with EPs 7630 compared to placebo patients. For instance, the EQ VAS increased by 34 units in the EPs 7630 group and by 24 units in the placebo group ( $p=0.001$ ). From the results of this study the authors concluded that EPs 7630 was superior in efficacy compared with placebo in the treatment of adults with acute bronchitis and may therefore offer an effective alternative treatment unless antibiotics are clearly indicated.

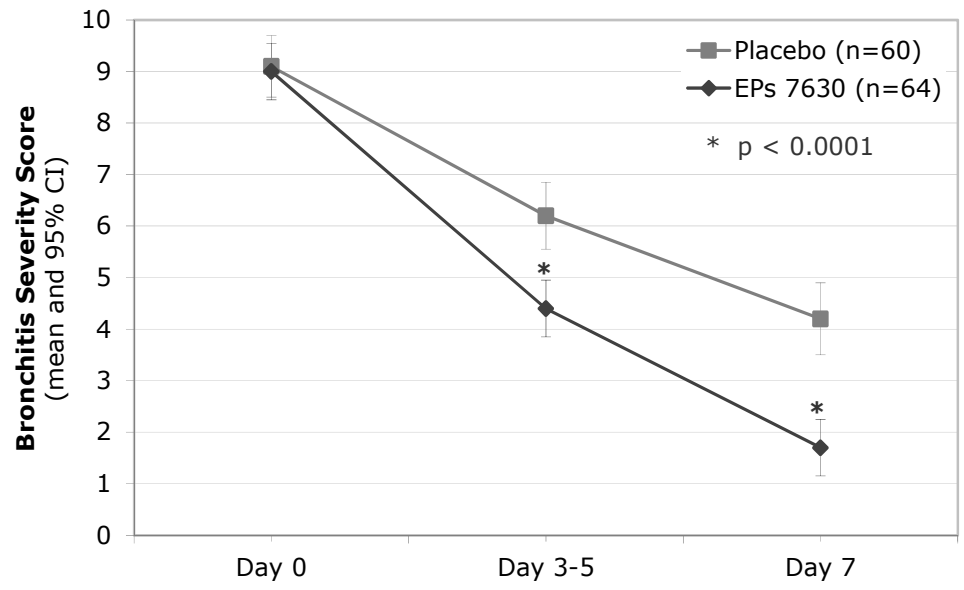

Fig. 3. Time course of the total Bronchitis Severity Score (BSS) during treatment ( $n=124$, ITT analysis)

In the second study, published by Matthys \& Heger (2007), 217 patients ( $\geq 18$ years) with acute bronchitis were randomised to the same dose regimen (either $3 \times 30$ drops/d EPs 7630 solution $(n=108)$ or matched placebo $(n=109)$ for a period of 7 days). At baseline, the mean total BSS was $8.9 \pm 1.6$ points in the active treatment group and $8.4 \pm 1.8$ points in the placebo group. Between baseline and day 7 , the mean total BSS decreased by $7.6 \pm 2.2$ points in the EPs 7630 group and $5.3 \pm 3.2$ points in the placebo group $(p<0.0001)$ (Figure 4$)$. The percentage of patients reporting complete remission of each of the five individual symptoms in the BSS on day 7 was higher in the EPs 7630 group (Figure 5). The difference between the two study groups was most pronounced for the symptoms coughing and rales at auscultation followed by sputum, dyspnoea and chest pain while coughing. For coughing $56 / 108(51.9 \%)$ of EPs 7630 patients versus $13 / 109(11.9 \%)$ of placebo patients reported a complete remission and none of the patients under EPs 7630 treatment had reported a 
deterioration compared to 5/109 (4.6\%) patients under placebo. For pulmonary rales at auscultation the complete remission rate was 82/93 (88.2\%) of EPs 7630 patients compared to $44 / 88(50.5 \%)$ of placebo patients. Similar results were noted for the general symptoms of acute bronchitis monitored. According to the IMOS assessment by the investigator on day 7 , complete recovery or major improvement was reported in $89.8 \%$ of EPs 7630 patients compared with $65.1 \%$ of placebo patients. The IMOS as assessed by the patient showed similar results. According to the IMPSS rating, 91/108 (84.3\%) of patients in the EPs 7630 group were very satisfied or satisfied with treatment in comparison with 52/109 (47.7\%) patients in the placebo group. The authors concluded that EPs 7630 solution was a well tolerated and effective treatment for acute bronchitis in adults outside the strict indication for an antibiotic therapy.

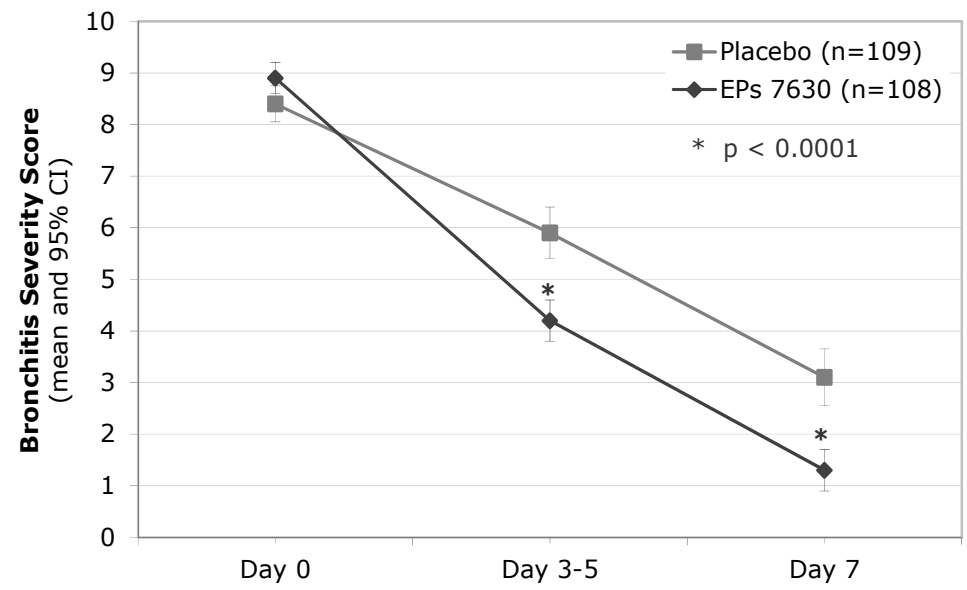

Fig. 4. Time course of the total Bronchitis Severity Score (BSS) during treatment ( $n=214$, ITT analysis)

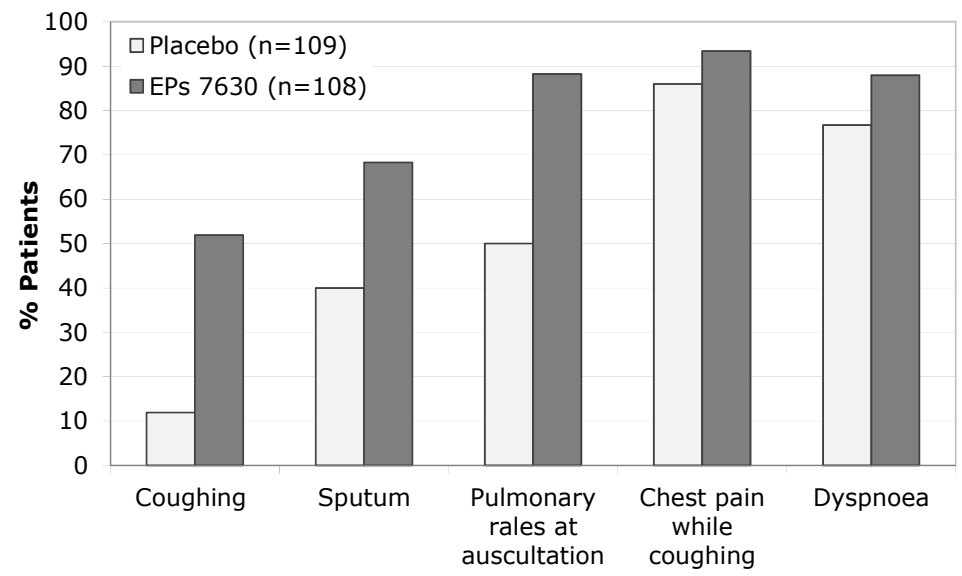

Fig. 5. Patients with complete remission of the individual bronchitis symptoms on day 7 
In a dose-finding study using an adaptive group-sequential design (Matthys et al., 2010b), 406 patients ( $\geq 18$ years) were randomly assigned to one of four parallel treatment groups (EPs 7630 film-coated tablets: 3x10mg (30mg group, 102 patients), 3x20mg (60mg group, 101 patients), or $3 \times 30 \mathrm{mg}$ (90mg group, 100 patients) or $3 \times$ placebo film-coated tablets (102 patients) daily for a treatment period of 7 days. 405 patients could be evaluated for the full analysis set. At baseline, the mean total BSS was similar in the four treatment groups (Figure 6). Between day 0 and day 7 , the mean total BSS decreased by $2.7 \pm 2.3$ points for placebo, $4.3 \pm 1.9$ points for the $30 \mathrm{mg}$ group, $6.1 \pm 2.1$ points for the $60 \mathrm{mg}$ group and $6.3 \pm 2.0$ points for the $90 \mathrm{mg}$ group, respectively. The tests of the global hypotheses including the pair-wise comparisons of each active treatment group to placebo applying ANCOVA analysis, revealed statistically significant differences for all EPs 7630 groups $(p<0.0001$, in each case, one-sided). A considerable difference in the total BSS for the EPs 7630 groups compared to placebo was already observed on day 3-5 and further increased to day 7 in a dosedependent manner.

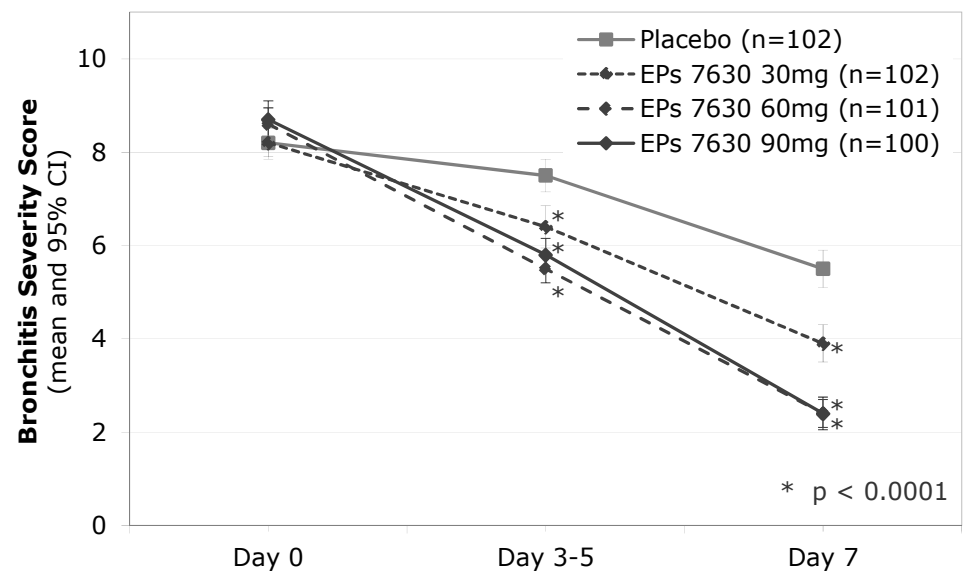

Fig. 6. Time course of the total Bronchitis Severity Score (BSS) during treatment ( $n=405$, ITT analysis)

The mean decrease in the five individual BSS items from day 0 to day 7 was markedly more pronounced in the active treatment groups compared to placebo. The reduction in the intensity of each symptom increased in a statistically significant way with the EPs 7630 dose ( $p<0.0001$, in each case, Bartholomew-test). Pair-wise comparison with placebo showed that the effect of EPs 7630 (complete remission and improvement) on coughing and pulmonary rales at auscultation from day 0 to day 7 was statistically significant $(\mathrm{p}<0.0001$, in each case, two-sided t-test). For sputum, chest pain while coughing and dyspnoea, statistically significant differences were observed between placebo and the $60 \mathrm{mg}$ and $90 \mathrm{mg}$ groups, respectively $(\mathrm{p}<0.0001$, in each case, two-sided $t$-test). A statistically significant dosedependent effect on the change in the general symptoms hoarseness $(p=0.0006)$, headache $(p=0.0001)$, limb pain $(p=0.032)$ and fatigue/exhaustion $(p=0.0001)$ from day 0 to day 7 could also be shown for EPs 7630 (Bartholomew-tests). The onset of treatment effect occurred significantly earlier in each EPs 7630 treatment group compared with placebo ( $p<0.0001$, in each case, two-sided Mantel-Haenszel $\chi^{2}$-test). In the placebo group, $42.2 \%$ of 
patients reported no treatment effect at all. The results of the investigator's assessment on day 7 according to treatment outcome (IMOS) showed a markedly higher rate of complete recovery and improvement in the active treatment groups compared with placebo $(p<0.0001$ for all pair-wise comparisons with placebo, two-sided Mantel-Haenszel $\chi^{2}$-test) (Figure 7). This applied to the patients' IMOS assessment as well. Evaluation of patients' satisfaction with treatment (IMPSS) on day 7 showed comparable results $(\mathrm{p}<0.0001$ for all pair-wise comparisons of the individual categories, two-sided Mantel-Haenszel $\chi^{2}$-test). The percentage of patients able to work at day 7 was significantly higher in all three EPs 7630 treatment groups compared to placebo $(\mathrm{p}<0.0001)$ (Figure 8). The median duration of inability to work was 8 days for placebo and 6 days for EPs 7630 treated patients, i.e. a reduction by 2 days could be seen in all active treatment groups $(p<0.0001$, in each case, two-sided U-test).
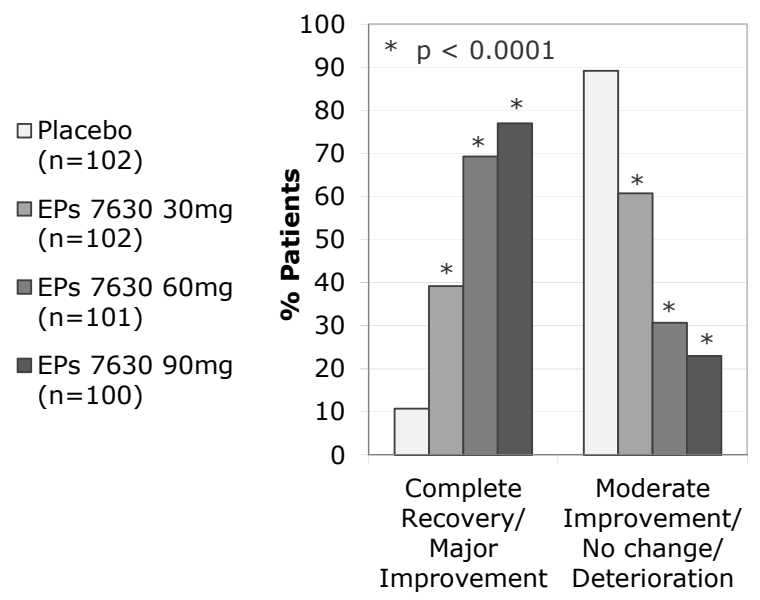

Fig. 7. Treatment outcome (IMOS): Assessment by the investigator on day 7 ( $p<0.0001$ for all pair-wise comparisons with placebo)
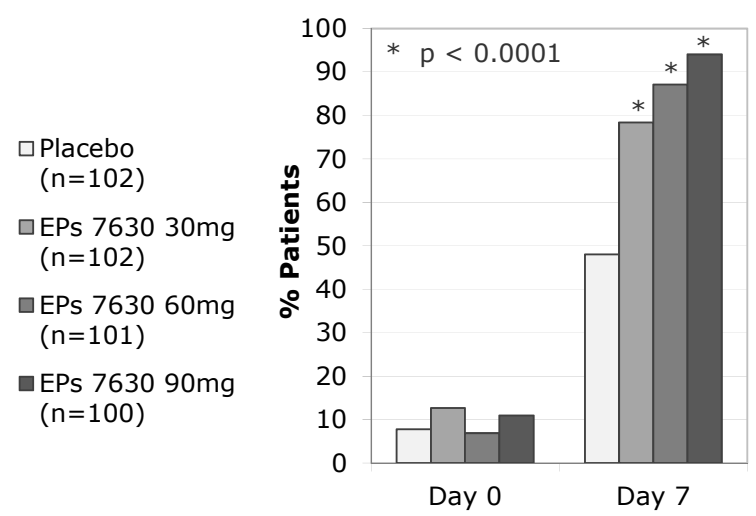

Fig. 8. Percentage of patients able to work on day 0 and day 7 , respectively $(p<0.0001$ compared to placebo) 
Across all five items of the EQ-5D questionnaire (mobility, self-care, usual activities, pain/discomfort, anxiety/depression), the number of patients with remission or improvement was significantly higher in the EPs 7630 treatment groups when compared with the placebo group ( $\mathrm{p}<0.05$ for all pair-wise comparisons, two-sided U-test) except for the symptom anxiety/depression in the $30 \mathrm{mg}$ and $60 \mathrm{mg}$ group for which the advantage was not significant (Matthys et al., 2010b). The assessment of the health status on a visual scale according to the EQ VAS on day 7 showed a significant higher improvement rate in the active treatment groups $(34.5 \pm 19.0 ; 41.4 \pm 18.9$ and $38.7 \pm 17.3$ in the $30 \mathrm{mg}, 60 \mathrm{mg}$ and $90 \mathrm{mg}$ group, respectively) compared to placebo $(20.0 \pm 18.9)(\mathrm{p}<0.0001$, two-sided Wilcoxon test) (Figure 9). The assessment of physical and mental health status according to the SF-12 revealed a much more pronounced improvement in the active treatment groups versus placebo for the physical component score $(\mathrm{p}<0.0001$ for all pair-wise comparisons with placebo, two-sided t-test). It was concluded that a daily dose of $60 \mathrm{mg}$ EPs 7630 could represent the optimal dose for EPs 7630 tablets with respect to the benefit-risk-ratio.

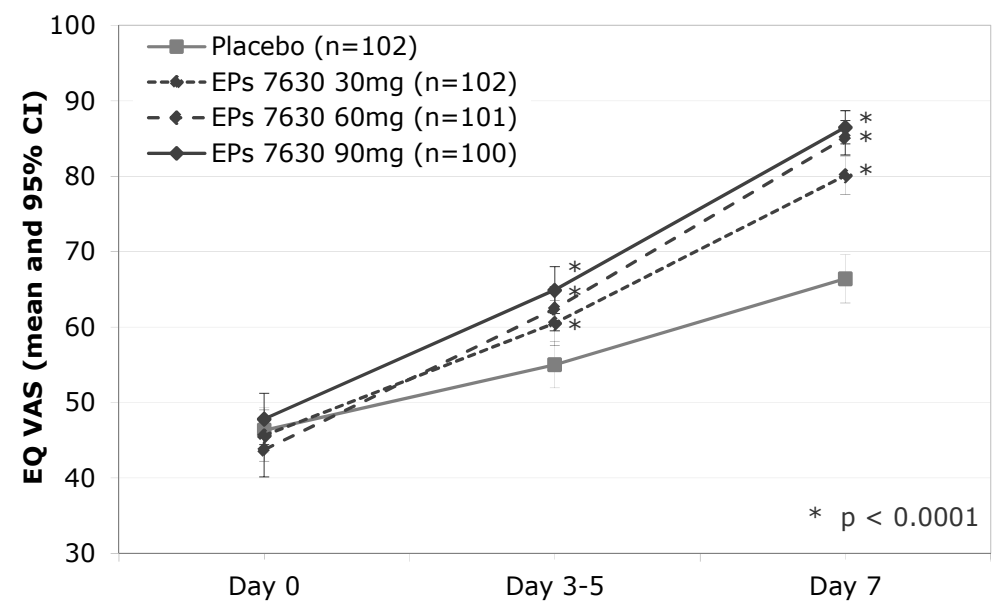

Fig. 9. Time course of health related quality of life: EQ VAS $(0=$ worst imaginable health state, $100=$ best imaginable health state; $n=405$, ITT analysis)

\subsection{Major randomised clinical trials in children and adolescents}

The two recently published major clinical studies in children and adolescents (Kamin et al., 2010a,b) are randomised, double-blind, placebo-controlled multicentre trials, which evaluated the efficacy and tolerability of EPs 7630 in children and adolescents (1-18 years) with acute bronchitis. Major inclusion criteria were a total BSS of $\geq 5$ points and acute bronchitis symptoms having started $\leq 48$ hours prior to study entry. The individual period of double-blind treatment lasted 7 days including three visits (day 0, day 3 to 5 , and day 7). The primary outcome parameter was the change in the total BSS from baseline to day 7 . Secondary outcome measures were the change in individual symptoms of the BSS; change of other general symptoms, e.g. headache, absence of appetite, and vomiting; treatment outcome assessed by both the patient or the legal representatives of the patients (patient's assessment) and the investigator using the Integrative Medicine Outcomes Scale (IMOS); patient's satisfaction with treatment using the Integrative Medicine Patient Satisfaction 
Scales (IMPSS); onset of treatment effect; ability to attend kindergarten, school or work, and quality of life by means of the FGK questionnaire (i.e. questionnaire for health state of children, which consists of 6 questions). In addition, adverse events (AEs), laboratory safety parameters, and vital parameters were documented.

In the first study (Kamin et al. 2010a), 200 children (EPs 7630: 103; placebo: 97) aged 1 to 18 years and suffering from acute bronchitis were randomly assigned and stratified to one of two parallel treatment groups according to age: Patients 1 to 6 years: $3 \times 10$ drops, patients $>6$ to 12 years: $3 \times 20$ drops, patients $>12-18$ years: $3 \times 30$ drops EPs 7630 per day or matched placebo for 7 consecutive days. For the statistical analysis, the total BSS comprising the objectively assessable three BSS items coughing, pulmonary rales at auscultation and dyspnoea was considered. At baseline, the mean total BSS was similar in both treatment groups (Figure 10). From baseline to day 7, the mean total BSS improved by $3.4 \pm 1.8$ points in the EPs 7630 group compared with $1.2 \pm 1.8$ points in the placebo group $(p<0.0001$, ANCOVA).

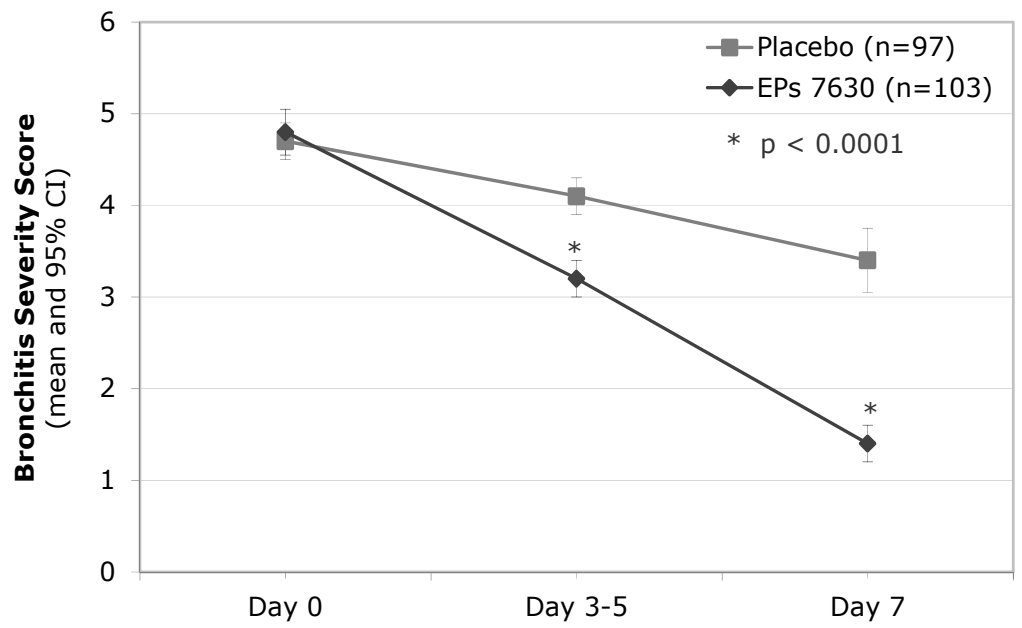

Fig. 10. Time course of the total Bronchitis Severity Score (BSS) during treatment $(n=200$, ITT analysis)

The decrease in the mean total BSS from day 0 to day 7 was more pronounced in the EPs 7630 group compared to placebo with significant differences in the individual symptoms coughing and pulmonary rales at auscultation in favour of the EPs 7630 group (both with p-values <0.0001, two-sided t-test). The assessment of general symptoms showed pronounced improvement in the active treatment group and was significant for the items absence of appetite and headache $(\mathrm{p}<0.0001$ and $\mathrm{p}=0.0003$, respectively, two-sided $\mathrm{t}$-test). The onset of treatment effect occurred significantly earlier in the EPs 7630 group as compared to placebo $\left(p<0.0001\right.$, two-sided Mantel-Haenszel $\chi^{2}$-test). The results of the evaluation of treatment outcome (IMOS) by the investigator at day 7 showed a significantly better IMOS outcome for patients treated with EPs 7630 than placebo $\left(\mathrm{p}<0.0001\right.$, two-sided Mantel-Haenszel $\chi^{2}$-test). The rates of patients showing complete recovery or major improvement were $77.7 \%$ for EPs 7630 and $19.6 \%$ for placebo (Figure 11). Patients' IMOS assessments showed a very strong agreement with the assessments 


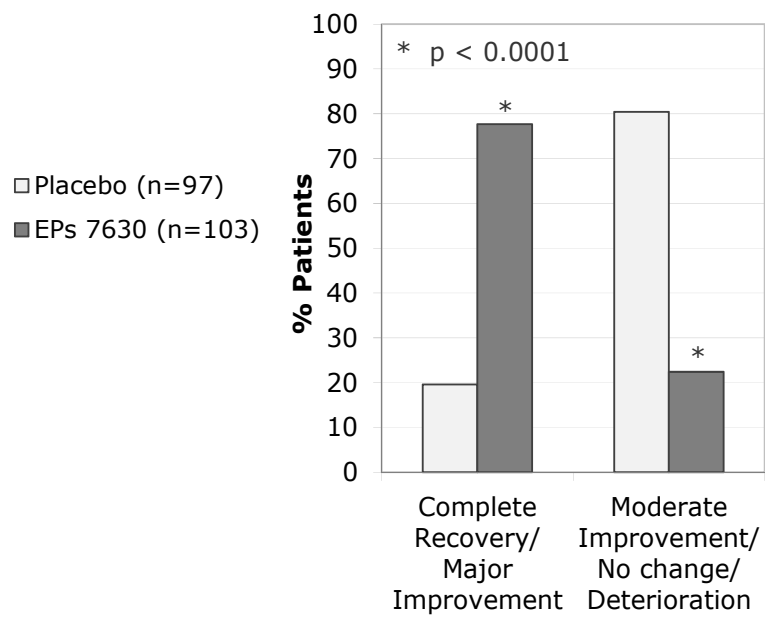

Fig. 11. Treatment outcome (IMOS), assessment by the physician on day 7

made by the investigators. In the EPs 7630 group, the number of patients keeping bed rest dropped from $42.7 \%(44 / 103)$ at baseline to $1.9 \%$ (2/103) patients on day 7 compared with a decrease from $42.3 \%$ (41/97) to $18.6 \%$ (18/97) for patients in the placebo group. Correspondingly, the number of patients able to attend kindergarten, school or work on day 7 increased more markedly in the EPs 7630 group than in the placebo group (50/103 patients $(48.5 \%)$ of the EPs 7630 group and 12/97 patients (12.4\%) of the placebo group) (Figure 12).

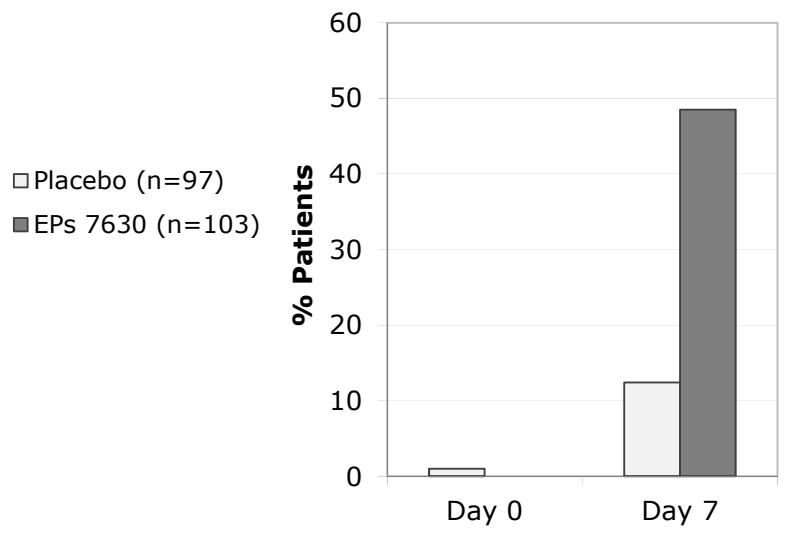

Fig. 12. Number of patients able to attend kindergarten, school or work on day 0 and on day 7 , respectively

The satisfaction of patients with treatment as assessed by the IMPSS on day 7 was also significantly positive in the EPs 7630 group ( $<<0.0001$, two-sided Mantel-Haenszel $\chi^{2}$-test) (Figure 13). Health status and quality of life as assessed by the FGK questionnaire showed 
significantly better results for the EPs 7630 group compared with placebo. For each FGK statement, namely "everything is too much for me" (1.0 \pm 1.2 vs. $0.3 \pm 1.3$ points, $\mathrm{p}<0.0001)$, "I am feeling ill" (1.8 \pm 0.8 vs. $1.0 \pm 1.1$ points, $\mathrm{p}<0.0001)$, "I am scared" ( $0.8 \pm 0.7$ vs. $0.3 \pm 0.9$ points, $\mathrm{p}=0.0002)$, "I have trouble playing or learning" ( $1.7 \pm 0.9$ vs. $0.8 \pm 1.1$ points, $\mathrm{p}<0.0001)$, "I sleep bad" (1.6 \pm 0.9 vs. $0.9 \pm 1.2$ points, $\mathrm{p}<0.0001)$ and "I have problems getting into conversation with others" $(1.2 \pm 1.0$ vs. $0.6 \pm 1.0$ points, $\mathrm{p}=0.0001)$, the two-sided t-test showed a significant advantage for the EPs 7630 group compared with placebo. The authors concluded that EPs 7630 was shown to be efficacious and safe in the treatment of acute bronchitis in children and adolescents outside the strict indication for antibiotics and that patients treated with EPs 7630 perceived a more favourable course of the disease and a good tolerability as compared with placebo.

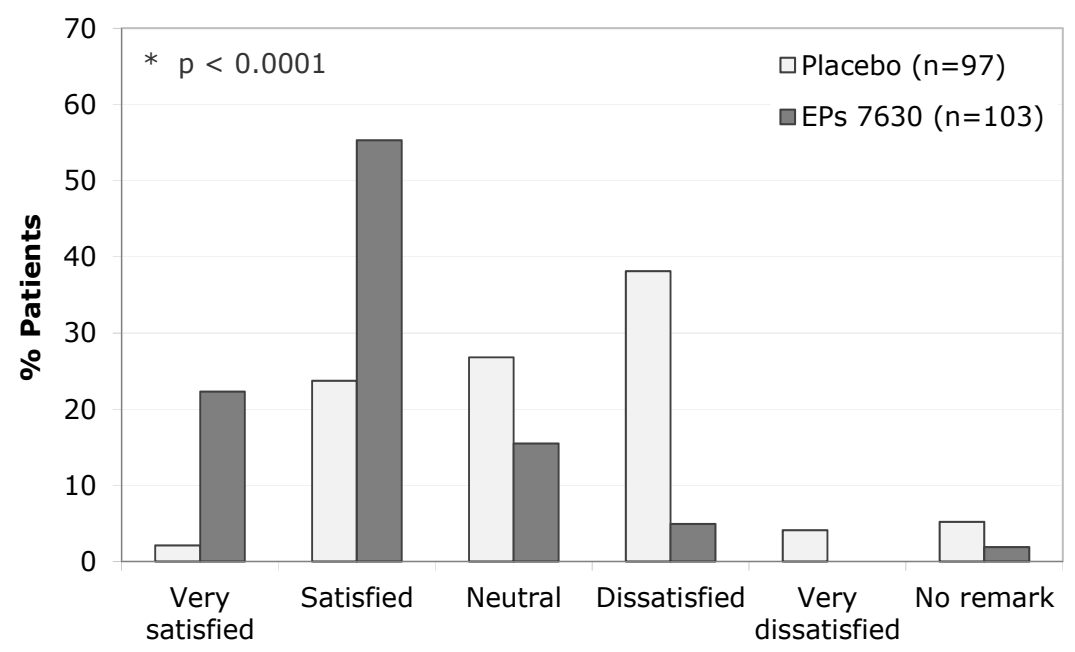

Fig. 13. Patients' satisfaction with treatment (IMPSS) on day 7

In the second study (Kamin et al., 2010b), which was a placebo-controlled clinical dosefinding trial, 400 children and adolescents (6-18 years) with acute bronchitis were randomly assigned to one of four parallel treatment groups and received EPs 7630 as filmcoated tablets at the following dose levels: $3 \times 10 \mathrm{mg}$ (=30mg group, 100 patients), 3x20mg (=60mg group, 99 patients) or $3 \times 30 \mathrm{mg} / \mathrm{d}$ (=90mg group, 99 patients) or matched placebo (101 patients) for 7 consecutive days. One patient in the 30mg group was an early drop out, thus the analysis included 399 patients. The evaluation of the total BSS comprised all five symptoms. At baseline, the mean total BSS was similar in the four treatment groups (Figure 14). The decrease in the mean total BSS between day 0 and day 7 was more pronounced in the active treatment groups as compared to the placebo group (placebo:

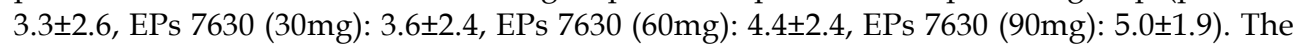
pair-wise comparisons of each active treatment group to placebo using the ANCOVA model revealed statistically significant differences in the decrease in the total BSS for the EPs $763060 \mathrm{mg}$ and $90 \mathrm{mg}$ group $(\mathrm{p}=0.0004$ and $\mathrm{p}<0.0001$, respectively, two-sided ANCOVA p-values). 


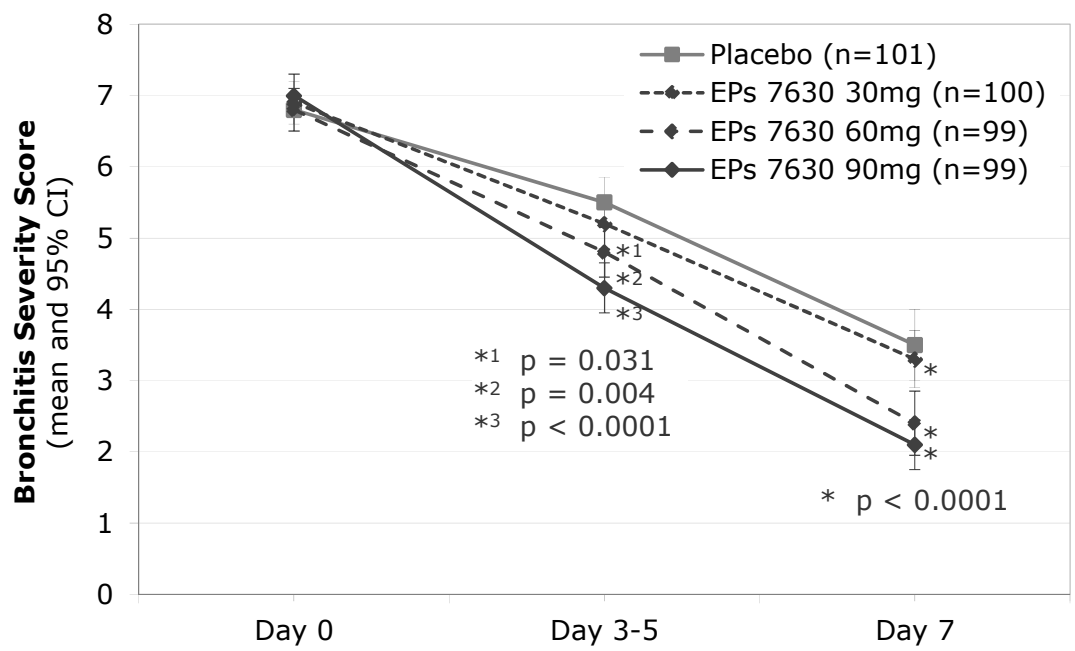

Fig. 14. Time course of the total Bronchitis Severity Score (BSS) during treatment $(n=399$, ITT analysis)

The mean decrease in the individual BSS items coughing, sputum, pulmonary rales at auscultation, chest pain while coughing and dyspnoea from day 0 to day 7 was markedly more pronounced in the EPs $7630(60 \mathrm{mg})$ and EPs $7630(90 \mathrm{mg})$ groups than in the placebo group. The active treatment groups showed a significant dose-dependent advantage compared to placebo for the symptoms coughing $(\mathrm{p}<0.0001)$, sputum $(\mathrm{p}=0.0016)$ and pulmonary rales at auscultation $(\mathrm{p}<0.0001$, two-sided $t$-test, each). A statistically significant dose-depending effect of EPs 7630 on the general symptoms absence of appetite $(p=0.0234)$, headache $(p=0.0112)$, vomiting $(p=0.0142)$ from day 0 to day 7 could also be shown (Bartholomew test). Patients in both the EPs $7630(60 \mathrm{mg})$ and EPs 7630 (90mg) groups reported an earlier onset of treatment effect $(p=0.0060$ and $p<0.0001$, respectively, two-sided Mantel-Haenszel $\chi^{2}$-test). Evaluation of the treatment outcome by the investigator using the IMOS showed a significantly better treatment outcome for the EPs $763090 \mathrm{mg}$ and $60 \mathrm{mg}$ groups than for placebo ( $\mathrm{p}=0.0005$ and $\mathrm{p}<0.0001$, respectively, two-sided Mantel-Haenszel $\chi^{2}$-test) (Figure 15). The IMOS results as assessed by the patient were comparable. The satisfaction of patients evaluated using IMPSS was better in the EPs 7630 groups compared with placebo. Patients were more often satisfied or very satisfied in the active treatment groups $(57.0 \%$ for EPs $7630(30 \mathrm{mg}), 66.7 \%$ for EPs 7630 (60mg), 81.8\% for EPs $7630(90 \mathrm{mg})$ ) than in the placebo group (45.5\%). Between day 0 and day 7 , the number of patients able to attend kindergarten, school or work improved markedly in all groups, especially in the EPs $7630(60 \mathrm{mg})$ and EPs 7630 (90mg) groups. At day 0 , only 1 patient (1\%) was able to attend kindergarten, school or work in the placebo and $60 \mathrm{mg}$ groups, respectively. At day 7,33.7\% (placebo), 35.0\% (EPs 7630 (30mg) group), $44.4 \%$ (EPs $7630(60 \mathrm{mg})$ group) and 53.5\% (EPs $7630(90 \mathrm{mg})$ group) had regained this ability (Figure 16). 

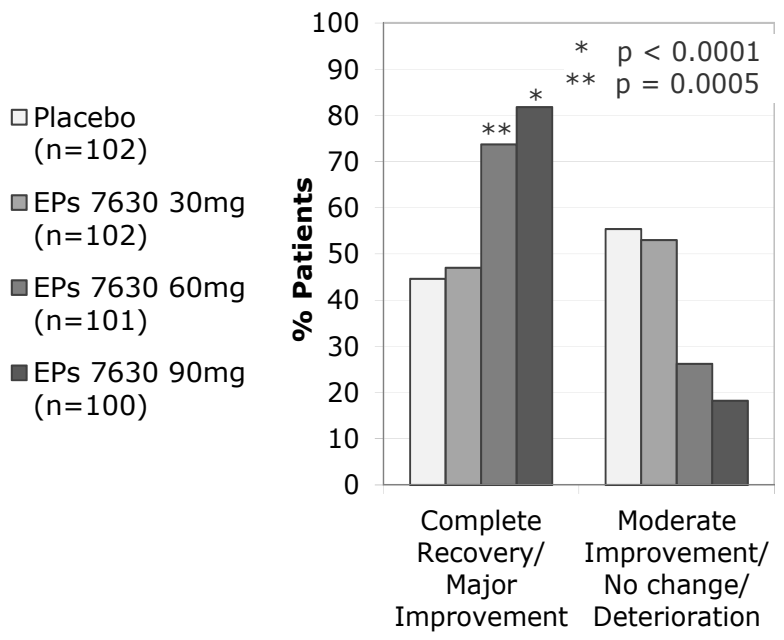

Fig. 15. Treatment outcome (IMOS), assessment by the physician on day 7
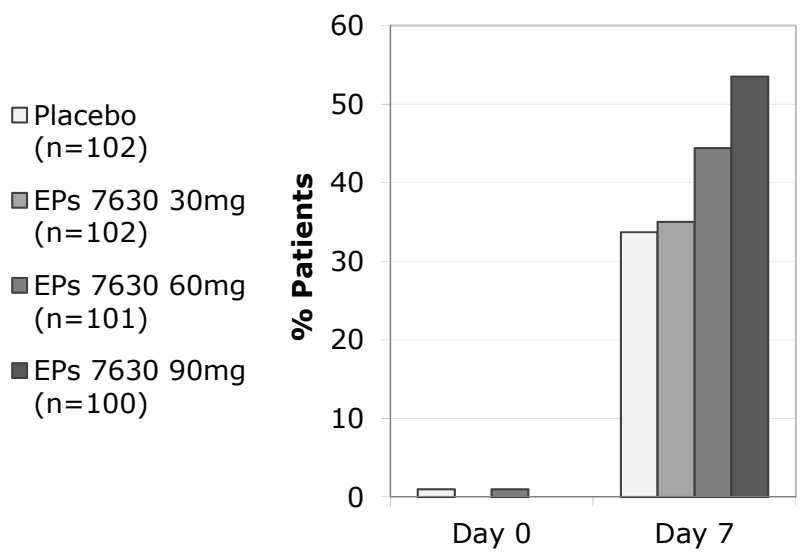

Fig. 16. Number of patients able to attend kindergarten, school or work on day 0 and on day 7 , respectively

In all groups, an improvement in health status as assessed by the FGK questionnaire could be seen between day 0 and day 7. This improvement was more pronounced in the EPs 7630 (60mg) and EPs 7630 (90mg) groups as compared with placebo. Based upon these findings the authors concluded that a daily dose of $60 \mathrm{mg}$ EPs 7630 (20mg three times per day) represents the optimal dose for the treatment of acute bronchitis in children and adolescents with respect to the benefit-risk-ratio.

\section{Safety and tolerability}

The safety profile of EPs 7630 has been systematically reviewed based upon 25 clinical trials and post-marketing surveillance studies with a total of more than 9,000 patients - including 
paediatric safety with about 4,000 children and adolescents - suffering from acute or exacerbation of chronic respiratory tract infections such as bronchitis, tonsillopharyngitis or sinusitis (Matthys \& Köhler, 2010). EPs 7630 was well tolerated and no serious adverse drug reactions were reported in this large patient population. Comparing EPs 7630 and placebo, adverse events were similar with regard to quality and quantity throughout almost all organ systems and symptoms, the only difference being a slightly higher incidence of gastrointestinal disorders (epigastric pain, nausea, diarrhoea) and of hypersensitivity reactions (mostly skin reactions), as well as gingival bleeding and epistaxis associated with EPs 7630 compared to placebo.

EPs 7630 is contraindicated during pregnancy and lactation due to a lack of safety data in this population, as well as in patients with hypersensitivity to the active substance or to any of the excipients. Up to now, there are no known contraindications to concomitant use of EPs 7630 with other medicinal products.

\section{Conclusion}

The results of the recently published high quality randomised clinical trials and independent meta-analyses show that EPs 7630 is an efficacious, safe, and well-tolerated herbal medicine in the management of acute respiratory tract infections (bronchitis, sinusitis, and tonsillopharyngitis) in children, adolescents and adults. The studies demonstrate both a statistically significant and clinically relevant superiority of EPs 7630 with respect to efficacy and a more favourable course of the disease and a faster recovery of patients compared to placebo. EPs 7630 was well tolerated and can therefore be considered to be a safe therapeutic alternative in the first-line treatment of acute bronchitis and as a reasonable choice for all patients outside the strict indication for antibiotics.

\section{References}

Abbas, S., Ihle, P., Heymans, L., Küpper-Nybelen, J. \& Schubert, I. (2010). Differences in antibiotic prescribing between general practitioners and pediatricians in Hesse, Germany. Deutsche Medizinische Wochenschrift, Vol. 135, pp. 1792-1797

Agbabiaka, T.B., Guo, R. \& Ernst, E. (2008). Pelargonium sidoides for acute bronchitis: a systematic review and meta-analysis. Phytomedicine, Vol. 15, No. 5, pp. 378-385

Bladt, S. \& Wagner, H. (2007). From the Zulu medicine to the European phytomedicine Umckaloabo $^{\circledR}$. Phytomedicine, Vol. 14(Suppl. VI), pp. 2-4

Brendler, T. \& van Wyk, B.-E. (2008). A historical, scientific and commercial perspective on the medicinal use of Pelargonium sidoides (Geraniaceae). Journal of Ethnopharmacology, Vol. 119, pp. 420-433

Brown, D. (2009). Pelargonium sidoides extract (EPs 7630): alternative treatment of acute upper respiratory tract infections. Natural Medicine Journal, Vol. 1, No. 4, pp. 1-6

Chuchalin, A.G., Berman, B. \& Lehmacher, W. (2005). Treatment of acute bronchitis in adults with a Pelargonium sidoides preparation $\left(\mathrm{EPS}^{\circledR} 7630\right.$ ): a randomized, double-blind, placebo-controlled trial. Explore, Vol. 1, No. 6, pp. 437-445 
Conrad, A., Hansmann, C., Engels, I., Daschner, F.D. \& Frank U. (2007a). Extract of Pelargonium sidoides $\left(\mathrm{EPs}^{\circledR}{ }^{\circledR} 7630\right)$ improves phagocytosis, oxidative burst, and intracellular killing of human peripheral blood phagocytes in vitro. Phytomedicine, Vol. 14(Suppl VI), pp. 46-51

Conrad, A., Jung, I., Tioua, D., Lallemand, C., Carrapatoso, F., Engels, I., Daschner, F.D. \& Frank, U. (2007b). Extract of Pelargonium sidoides (EPs $\left.{ }^{\circledR} 7630\right)$ inhibits the interactions of group A-streptococci and host epithelia in vitro. Phytomedicine, Vol. 14(Suppl VI), pp. 52-59

EQ-5D. A standardised instrument for use as a measure of health outcome. Available via http://www.euroqol.org/. Last accessed 04 March 2011

Franks, P. \& Gleiner, J.A. (1984). The treatment of acute bronchitis with trimethoprim and sulfamethoxazole. The Journal of Family Practice, Vol. 19, No. 2, pp. 185-190

Kamin, W., Maydannik, V., Malek, F.A. \& Kieser, M. (2010a). Efficacy and tolerability of EPs 7630 in children and adolescents with acute bronchitis: a randomized, double-blind, placebo-controlled multicenter trial with a herbal drug preparation from Pelargonium sidoides roots. International Journal of Clinical Pharmacology and Therapeutics, Vol. 48, No. 3, pp. 184-191

Kamin, W., Maydannik, V.G., Malek, F.A. \& Kieser, M. (2010b). Efficacy and tolerability of EPs 7630 in patients (aged 6-18 years old) with acute bronchitis: a randomized, double-blind, placebo-controlled clinical dose-finding study. Acta Paediatrica, Vol. 99, No. 4, pp. 537-543

Knutson, D. \& Braun, C. (2002). Diagnosis and management of acute bronchitis. American Family Physician, Vol. 65, No. 10, pp. 2039-2044

Koch, E. \& Biber, A. (2007). Treatment of rats with the Pelargonium sidoides extract $\mathrm{EPs}^{\circledR} 7630$ has no effect on blood coagulation parameters or on the pharmacokinetics of warfarin. Phytomedicine, Vol. 14(Suppl VI), pp. 40-45

Koch, E., Lanzendörfer-Goossens, H. \& Wohn, C. (2002). Stimulation of interferon (INF)-ß-synthesis and natural killer (NK) cell activity by an aqueous-ethanolic extract from roots of Pelargonium sidoides (Umckaloabo ${ }^{\circledR}$ ). NaunynSchmiedeberg's Archives of Pharmacology, Vol. 365(Suppl 1), R75

Koch, E. \& Wohn, C. (2007) Pelargonium sidoides root extract EPs ${ }^{\circledR} 7630$ stimulates release of antimicrobial peptides from neutrophil granulocytes in human whole blood. Planta Medica, Vol. 73, pp. 846

Kolodziej, H. (2007). Fascinating metabolic pools of Pelargonium sidoides and Pelargonium reniforme, traditional and phytomedicinal sources of the herbal medicine Umckaloabo ${ }^{\circledR}$. Phytomedicine, Vol. 14(Suppl VI), pp. 9-17

Kolodziej, H., Kayser, O., Radtke, O.A., Kiderlen, A.F. \& Koch, E. (2003). Pharmacological profile of extracts of Pelargonium sidoides and their constituents. Phytomedicine, Vol. 10(Suppl IV), pp. 18-24

Kolodziej, H. \& Kiderlen, A.F. (2007). In vitro evaluation of antibacterial and immunomodulatory activities of Pelargonium reniforme, Pelargonium sidoides and the related herbal drug preparation EPs ${ }^{\circledR}$ 7630. Phytomedicine, Vol. 14(Suppl VI), pp. 18-26 
Kolodziej, H. \& Schulz, V. (2003). Umckaloabo. Deutsche Apotheker Zeitung, Vol. 143, No. 12, pp. 55-64

Little, P. (2005). Delayed prescribing of antibiotics for upper respiratory tract infection. British Medical Journal, Vol. 331, No. 7512, pp. 301-302

Macfarlane, J., Holmes, W., Gard, P., Thornhill, D., Macfarlane, R. \& Hubbard, R. (2002). Reducing antibiotic use for acute bronchitis in primary care: blinded, randomised controlled trial of patient information leaflet. British Medical Journal, Vol. 324, No. 7923, pp. 91-94

Matthys, H. \& Heger, M. (2007). Treatment of acute bronchitis with a liquid herbal drug preparation from Pelargonium sidoides (EPs 7630): a randomised, doubleblind, placebo-controlled, multicentre study. Current Medical Research and Opinion, Vol. 23, No. 2, pp. 323-331

Matthys, H. \& Köhler, S. (2010). Safety and tolerability of EPs ${ }^{\circledR} 7630$ (Umckaloabo ${ }^{\circledR}$ ). Planta Medica, Vol. 76, No. 12, SL29. DOI: 10.1055/s-0030-1264267

Matthys, H., Lizogub, V.G., Funk, P. \& Malek, F.A. (2010a). Pelargonium sidoides in acute bronchitis - Health-related quality of life and patient-reported outcome in adults receiving EPs 7630 treatment. Wiener Medizinische Wochenschrift, Vol. 160, No. 21-22, pp. 564-570

Matthys, H., Lizogub, V.G., Malek, F.A. \& Kieser, M. (2010b). Efficacy and tolerability of EPs 7630 tablets in patients with acute bronchitis: a randomised, double-blind, placebo-controlled dose-finding study with a herbal drug preparation from Pelargonium sidoides. Current Medical Research and Opinion, Vol. 26, No. 6, pp. 1413-1422

Michaelis, M., Doerr, H.W. \& Cinatl, J. Jr. (2011). Investigation of the influence of EPs ${ }^{\circledR}$ 7630, a herbal drug preparation from Pelargonium sidoides, on replication of a broad panel of respiratory viruses. Phytomedicine, Vol. 18, No. 5, pp. 384-386

Neugebauer, P., Mickenhagen, A., Siefer, O. \& Walger, M. (2005). A new approach to pharmacological effects on ciliary beat frequency in cell cultures - exemplary measurements under Pelargonium sidoides extract (EPs 7630). Phytomedicine, Vol. 12, No. 1-2, pp. 46-51

Nöldner, M. \& Schötz, K. (2007). Inhibition of lipopolysaccharid-induced sickness behavior by a dry extract from the roots of Pelargonium sidoides (EPs $\left.{ }^{\circledR} 7630\right)$ in mice. Phytomedicine, Vol. 14(Suppl VI), pp. 27-31

Schoetz, K., Erdelmeier, C., Germer, S. \& Hauer, H. (2008). A detailed view on the constituents of EPs ${ }^{\circledR}$ 7630. Planta Medica, Vol. 74, No. 6, pp. 667-674

Sechehaye, A. (1937). Die Behandlung der organischen und chirurgischen Tuberkulose durch Umckaloabo. (2. Auflage), Meyer \& Co. Verlag, Leipzig

Steinsbekk, A., Biolchini, J., Heger, M., Rezzani, C., Tsamis, N., van Haselen, R., Witt, C. \& Wittorff, M. (1999). European Committee for Homeopathy. Data Collection in Homeopathic Practice. Available via http://www.scribd.com/doc/49190379/ECH-Proposal-for-Data-Collection-inHomeopathic-Practice. Last accessed 04 March 2011

Thäle, C., Kiderlen, A.F. \& Kolodziej, H. (2011). Anti-infective activities of Pelargonium sidoides $\left(\mathrm{EPs}^{\circledR} 7630\right)$ : Effects of induced NO production on Leishmania major in 
infected macrophages and antiviral effects as assessed in a Fibroblast-virus protection assay. Planta Medica, Vol. 77, No. 7, pp. 718-725

Timmer, A., Günther, J., Rücker, G., Motschall, E., Antes, G. \& Kern, W.V. (2008). Pelargonium sidoides extract for acute respiratory tract infections. Cochrane Database of Systematic Reviews 2008, Issue 3. Art. No.: CD006323. DOI: 10.1002/14651858.CD006323.pub2

Ware, J.E. Jr., Kosinski, M. \& Keller, S.D. (1996). A 12-Item Short-Form Health Survey: construction of scales and preliminary tests of reliability and validity. Medical Care, Vol. 34, No. 3, pp. 220-233

Williamson, H.A. Jr. (1984). A randomized, controlled trial of doxycycline in the treatment of acute bronchitis. The Journal of Family Practice, Vol. 19, No. 4, pp. $481-486$ 


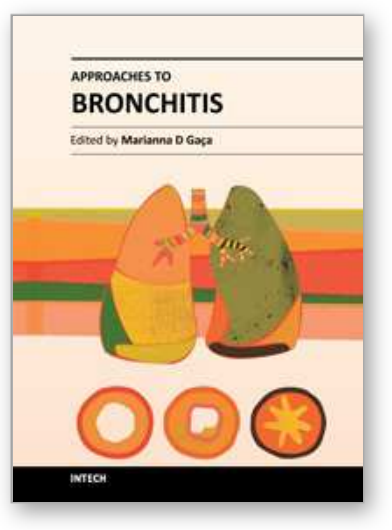

\author{
Approaches to Bronchitis \\ Edited by Prof. Marianna GaÃßa
}

ISBN 978-953-307-770-3

Hard cover, 70 pages

Publisher InTech

Published online 17, October, 2011

Published in print edition October, 2011

The aim of this book is to present some recent and interesting findings in the field of bronchitis, which will serve as a supplement to the book Bronchitis. In particular, this volume focuses on the successful use and development of novel tools in the diagnostics and treatment of bronchitis. Contributions include clinical case studies, the impact of air pollution on bronchitis, the presentation and diagnosis of the respiratory disease eosinophilic bronchiolitis, primary ciliary dyskinesia, the development of a method for the swift detection of the infectious bronchitis virus and studies investigating the successful use of alternative medicines in the treatment of bronchitis. The editor would like to thank the authors of the chapters who have contributed to this book and hopes that this will book not only supplement the book on Bronchitis, but may increase interest in the subject.

\title{
How to reference
}

In order to correctly reference this scholarly work, feel free to copy and paste the following:

H. Matthys and W. Kamin (2011). EPs 7630, a Herbal Drug Preparation for Treating Acute Bronchitis in Children and Adults, Approaches to Bronchitis, Prof. Marianna GaÃßa (Ed.), ISBN: 978-953-307-770-3, InTech, Available from: http://www.intechopen.com/books/approaches-to-bronchitis/eps-7630-a-herbal-drugpreparation-for-treating-acute-bronchitis-in-children-and-adults

\section{INTECH}

open science | open minds

\section{InTech Europe}

University Campus STeP Ri

Slavka Krautzeka 83/A

51000 Rijeka, Croatia

Phone: +385 (51) 770447

Fax: +385 (51) 686166

www.intechopen.com

\section{InTech China}

Unit 405, Office Block, Hotel Equatorial Shanghai

No.65, Yan An Road (West), Shanghai, 200040, China

中国上海市延安西路65号上海国际贵都大饭店办公楼405单元

Phone: +86-21-62489820

Fax: +86-21-62489821 
(C) 2011 The Author(s). Licensee IntechOpen. This is an open access article distributed under the terms of the Creative Commons Attribution 3.0 License, which permits unrestricted use, distribution, and reproduction in any medium, provided the original work is properly cited. 